\title{
Effects of Crop Management Practices on Current-Season Spread of Potato virus $Y$
}

Tyler D. B. MacKenzie, Agricultural Certification Services Inc., Fredericton, NB, E3B 8B7, Canada; Manphool S. Fageria and Xianzhou Nie, Potato Research Centre, Agriculture and Agri-Food Canada, Fredericton, NB, E3B 4Z7 Canada; and Mathuresh Singh, Agricultural Certification Services Inc., Fredericton

\begin{abstract}
MacKenzie, T. D. B., Fageria, M. S., Nie, X., and Singh, M. 2014. Effects of crop management practices on current-season spread of Potato virus Y. Plant Dis. 98:213-222.

The current-season spread of Potato virus Y (PVY) was monitored in 19 fields under various management practices in New Brunswick, Canada, through the 2011 and 2012 growing seasons. The focus of this study was to evaluate the role of seedborne PVY inoculum, aphid vector abundance, and the numbers, timing, and types of insecticide and mineral oil sprays, and to confirm the reliability and forecasting capacity of midseason PVY testing. In each field, 100 to 110 virus-free plants were identified shortly after emergence and were assessed four times from early July to early September (after top-kill) with enzymelinked immunosorbent assay (ELISA) and reverse-transcription polymerase chain reaction (RT-PCR) to track PVY spread. In addition, tubers harvested during development in August and after top-kill were grown-out in the greenhouse for ELISA testing. PVY spread to selected virus-free plants varied widely, ranging from 0 to $76.2 \%$ across all studied fields. Of the 19 fields over two seasons, 10 fields were planted with no detectable seedborne PVY, and they showed 0 to $8.7 \%$ (mean $2.9 \%$ ) PVY spread by harvest. The remaining nine study fields with 0.9 to $5.8 \%$ seedborne PVY showed 1 to $76.2 \%$ (mean $15.2 \%$ ) PVY spread by harvest. PVY spread was detected in most fields during

midseason testing with ELISA and RT-PCR; all tests correlated well with final PVY rates after top-kill, though RT-PCR detection in developing tubers was most sensitive and correlated. Logistic regression modeling was used to identify major factors in PVY spread, including seedborne PVY, early-season aphid abundance, and the numbers of insecticide and mineral oil sprays. The best-fitting model, constructed using these factors as well as a measurement of July PVY incidence $\left(\right.$ ELISA $_{\text {July }}$ ), strongly explained PVY spread by harvest, with the most significant management factor being the number of mineral oil sprays supplemented with insecticide used during the growing season. A simi-

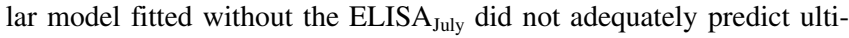
mate PVY spread. The analysis suggests that mineral oil alone was effective at lowering PVY spread, and more effective when combined with insecticide, particularly when used early in the season. No evidence was found for differences in PVY spread across the eight cultivars used or across the range of mineral oil application rates, whereas some evidence was found for differences in the effectiveness of different insecticide types.
\end{abstract}

Potato virus $Y$ (PVY) is the type member of the Potyvirus genus in the family Potyviridae. Its distribution has been widespread across the potato-growing regions of the world for many decades, and it remains one of the most economically damaging plant viruses in the world today (11). In recent years, current-season spread of PVY in New Brunswick, Canada, has become a major concern (16).

Aphids are the vector for transmitting PVY between potato plants, and their abundance in the field has been shown to significantly increase PVY incidence (5). Many species of aphids, including several of the abundant species in our study region, can transmit PVY $(6,9,18)$. To date, at least 65 species of aphids have been identified to be capable of carrying PVY $(36,39)$, and presumably many, if not all, of them can transmit the virus to potato plants. Aphids acquire PVY while probing the plants with their stylets. The virus may remain in the stylet for only a short period of time, and is lost to the point of no longer being infectious after the aphid probes one to several other plants (19).

Keeping PVY inoculum low at the initial stage of crop growth and then managing on-farm spread of virus by aphids during the crop season are considered to be the most important factors for effective management of PVY (37). Important management practices may include planting certified seed potatoes, sanitation of planting equipment, destroying over wintering sources of PVY

Corresponding author: M. Singh, E-mail: msingh@ potatoesnb.com

Accepted for publication 21 August 2013.

http://dx.doi.org/10.1094/PDIS-04-13-0403-RE

(C) 2014 The American Phytopathological Society inoculum, using crop borders $(7,13,14,17,23)$, and timely rogueing of volunteer potato plants and weed reservoirs of aphids and virus (12). Spraying of contact insecticides $(20,28)$ and mineral oils $(2,3,8,19,22,27)$ has been widely studied for its effectiveness at limiting the spread of PVY within the field. Nevertheless, the effectiveness of contact insecticides may be limited, because the aphids may not be killed quickly enough to prevent them from transmitting PVY $(27,37)$. In contrast, mineral oils have been found to be more effective in reducing PVY transmission and, thus, have been used widely for PVY management in potato crops. Although the exact mechanism of oils is still debated (1), several hypotheses, including delaying aphid stylet penetration of leaf tissue $(8,38)$, modifying aphid behavior to limit PVY acquisition and transmission $(2,3,19,27)$, physically altering the retention of virus in the stylet (45), and even through direct insecticidal properties (29).

A survey of seed potato growers in New Brunswick, Canada, in January 2011 for PVY incidence based on post-harvest virus test (PHVT) results indicated a significant variation in PVY incidence between farms. It was found that crop management practices used by them also varied, which may have contributed to the significantly different PHVT results. Therefore, the main objective of this study was to evaluate the role of crop management practices, especially seedborne PVY inoculum and use of mineral oil and insecticide sprays, on current-season spread of PVY in this region, and to develop a statistical model to explain PVY spread.

\section{Materials and Methods}

Selection of fields, cultivar, and sample collection. Ten potato fields managed by different growers and separated widely across the potato-growing region of New Brunswick, Canada were selected for the study in the 2011 crop season. The fields consisted 
of: two fields of 'CalWhite'; one field of each of 'FL1207', 'Innovator', 'Shepody', and 'Russet Burbank'; and four fields of 'Goldrush'. These cultivars are generally considered susceptible to PVY infection but were chosen by the growers and are representative of the majority of potato production in the region. All fields were planted between 21 May and 11 June 2011 and imidacloprid (Admire) was used as an in-furrow insecticide at the recommended rate. These fields were selected to represent the widest practical range of management practices, common cultivars, and locations within this potato-growing region to test our initial hypotheses arising from PHVT.

After the initial results from the 2011 field season, the study narrowed focus onto a more controlled experiment involving three growers using categorically different mineral oil and insecticide spray schedules. Each grower maintained three adjacent fields, two under the grower's typical mineral oil and insecticide spraying regime and the remaining one as a control field in which no sprays were applied. The cultivars in the 2012 crop season included one field each of Shepody and 'Snowden', three fields of Innovator, and two fields each of Russet Burbank and FL1879. These fields were planted between 21 and 27 May 2012, also all with imidacloprid (Admire) as an in-furrow application at the recommended rate.

Although the selection criteria of the fields and experimental rationale were different between 2011 and 2012, the field sampling protocol was the same for both years (15). The dates of planting varied across the fields due to weather and grower choice. In 2011, fields were planted in two distinct groups between about 21 to 30 May and 2 to 11 June; in 2012, all fields were planted within a week between 21 and 27 May. Initial sampling dates in 2011 were on 27 June and 7 July for the early- and late-planted fields, respectively. In 2012, initial sampling occurred on 3 July for all fields. These dates were chosen to ensure that the plants were at a similar maturity level at sampling despite their different planting dates. For the initial sampling in each field, 100 to 110 potato plants were arbitrarily selected and flagged from six rows (20 plants/row, plants roughly $6 \mathrm{~m}$ apart in a row). Two leaves from each plant were collected and tested for PVY using enzyme-linked immunosorbent assay (ELISA) to quantify the incidence of seedborne PVY. Plants that tested positive at this step were excluded from further investigation, and a minimum of 100 initially PVY-free plants from each field were then monitored throughout the growing season. From these virus-free plants, leaf samples were collected twice during the growing season (in July and August) and evaluated for the presence of PVY using ELISA and reverse-transcription polymerase chain reaction (RT-PCR). In 2011, the July samplings occurred on 19 and 27 July in early- and late-planted fields, respectively, whereas, in 2012, all fields were sampled on 26 July. This sampling was to provide an early indication of virus spread to the previously marked virus-free plants, and the dates were selected to ensure a standardized period of 20 to 23 days to allow for that spread. During the August sampling, leaves and two developing tubers were taken from each marked plant on 8 and 11 August in early- and late-planted fields in 2011 and 20 to 22 August 2012. Plants were top-killed on grower-chosen dates, from 24 August to 8 September 2011 and 28 August to 7 September 2012. Three dormant tubers were taken from each marked plant 1 to 2 weeks after top-kill. Tubers collected in August and September were tested for PVY using RT-PCR shortly after collection. After a dormancy break (30), the same tubers were planted in the greenhouse (ambient day and night cycle, 22 to $25^{\circ} \mathrm{C}$ ) for grow-out testing. The leaves of the plants that grew out from the tubers were tested for PVY using ELISA.

Practices used by growers in study fields. A range of management practices across all the fields were used by different growers, with the number and timing of mineral oil and insecticide sprays being of greatest interest in this study. Growers sprayed a variety of insecticides with their recommended doses, mostly of the $\lambda$ cyhalothrin (Matador and Silencer) and flonicamid (Beleaf) chemistries that have been shown to be effective at rapid aphid incapacitation in some studies (1). Several of the growers used

Table 1. Summary of management practices used, aphid abundance, and seedborne Potato virus Y (PVY) detected in each field ${ }^{\mathrm{B}}$

\begin{tabular}{|c|c|c|c|c|c|c|c|c|c|c|c|}
\hline \multirow[b]{2}{*}{ Season, cultivar ${ }^{c}$} & \multicolumn{2}{|c|}{$\begin{array}{l}\text { Number } \\
\text { of sprays }\end{array}$} & \multicolumn{2}{|c|}{$\begin{array}{c}\text { First application } \\
\text { (days after planting) }\end{array}$} & \multicolumn{2}{|c|}{$\begin{array}{c}\text { Last application (days } \\
\text { before top-kill) }\end{array}$} & \multirow[b]{2}{*}{ Liters/ha ${ }^{\mathbf{d}}$} & \multicolumn{3}{|c|}{$\begin{array}{c}\text { Aphids } \\
(\text { per trap per week })^{b}\end{array}$} & \multirow[b]{2}{*}{$\operatorname{PVY}(\%)^{\mathrm{e}}$} \\
\hline & Oil & IC & Oil & IC & Oil & IC & & Early & Mid & Late & \\
\hline \multicolumn{12}{|l|}{2011} \\
\hline Russet Burbank & 0 & 0 & $\ldots$ & $\ldots$ & $\ldots$ & $\ldots$ & $\ldots$ & 8.0 & 8.7 & 16.3 & 5.8 \\
\hline Innovator & 13 & 9 & 23 & 29 & 7 & 22 & 4.5 & 21.3 & 7.0 & 12.9 & 0 \\
\hline Goldrush 1 & 7 & 3 & 43 & 61 & 6 & 32 & 2.5 & 25.7 & 19.7 & 20.1 & 0 \\
\hline Goldrush 2 & 14 & 14 & 25 & 25 & 6 & 6 & 5 & 22.5 & 41.6 & 32.9 & 0 \\
\hline FL1207 & 16 & 2 & 26 & 49 & 0 & 2 & 2.5 & 11.1 & 14.2 & 14.3 & 0.8 \\
\hline Shepody & 8 & 3 & 32 & 41 & 8 & 8 & 3.7 & 26.6 & 7.7 & 13.8 & 5.8 \\
\hline Goldrush 3 & 14 & 2 & 14 & 39 & 2 & 47 & 5 & 7.3 & 3.5 & 8.8 & 0 \\
\hline Goldrush 4 & 12 & 4 & 25 & 46 & 9 & 24 & 3.7 & 28.3 & 18.8 & 48.2 & 0 \\
\hline CalWhite 1 & 6 & 3 & 30 & 36 & 22 & 14 & 1.7 & 6.5 & 12.8 & 10.0 & 0 \\
\hline CalWhite 2 & 10 & 3 & 25 & 32 & 8 & 43 & 2.5 & 13.4 & 9.4 & 12.7 & 2.5 \\
\hline Median & 12 & 3 & 25 & 39 & 7 & 22 & 3.7 & 17.4 & 11.1 & 14.1 & 0 \\
\hline \multicolumn{12}{|l|}{2012} \\
\hline Shepody & 10 & 0 & 35 & $\ldots$ & 4 & $\ldots$ & 5 & 81.8 & 29.0 & 18.5 & 0.9 \\
\hline Innovator 1 & 10 & 0 & 27 & $\ldots$ & 4 & $\ldots$ & 5 & 32.5 & 13.8 & 18.3 & 0 \\
\hline Innovator 2 & 0 & 0 & $\ldots$ & $\ldots$ & $\ldots$ & $\ldots$ & $\ldots$ & 127.8 & 44.5 & 24.2 & 4.5 \\
\hline Snowden & 11 & 11 & 26 & 26 & 9 & 9 & 3.7 & 7.0 & 16.3 & 6.3 & 0.9 \\
\hline Innovator 3 & 11 & 11 & 26 & 26 & 9 & 9 & 3.7 & 5.5 & 14.8 & 7.3 & 0 \\
\hline Russet Burbank 1 & 0 & 0 & $\ldots$ & $\ldots$ & $\ldots$ & $\ldots$ & $\ldots$ & 6.8 & 12.0 & 13.3 & 0.9 \\
\hline FL1879 1 & 10 & 3 & 31 & 42 & 7 & 48 & 2.5 & 37.3 & 22.0 & 21.2 & 1.8 \\
\hline FL1879 2 & 10 & 3 & 31 & 42 & 7 & 48 & 2.5 & 32.8 & 22.0 & 17.0 & 0 \\
\hline Russet Burbank 2 & 0 & 0 & $\ldots$ & $\ldots$ & $\ldots$ & $\ldots$ & $\ldots$ & 155.8 & 17.0 & 24.2 & 0 \\
\hline Median & 10 & 7 & 29 & 34 & 7 & 28.5 & 3.7 & 32.8 & 17.0 & 18.3 & 0.9 \\
\hline Median (2011-12) & 10 & 3 & 26 & 39 & 7 & 22 & 3.7 & 22.5 & 14.8 & 16.3 & 0 \\
\hline
\end{tabular}

a Oil = mineral oil and $\mathrm{IC}=$ insecticide.

b Aphids were collected in two to eight traps per field, sampled two to three times per week. Aphid abundance here is calculated by dividing the total number of aphids trapped during the time period by the number of traps and length of the period. Early $=20$ June to 3 July, Mid $=4$ to 17 July, and Late $=18$ July to 7 August.

${ }^{c}$ Field season, cultivar, and field.

${ }^{\mathrm{d}}$ Mineral oil application rate.

e Seedborne PVY. 
other pyrethroids (Decis and Pounce) and, occasionally, other nonpyrethroid contact insecticides (Lagon and Thionex). Mineral oil sprays, typically with Superior-70 oil (N. M. Bartlett Inc.), were applied at 1.7 to 5 liters/ha ( 1.5 and $2.0 \%$ as tank mix) at widely varying dates and numbers of spray applications in nine and six of the fields in 2011 and 2012, respectively, and did not occur at all in one and three fields in 2011 and 2012, respectively, which were used as controls. Spray schedules of mineral oil and insecticide are given in Table 1. This wide variation in management practices allows us to assess the efficacy of mineral oil and insecticide spraying for controlling PVY spread. Other management practices, such as application of insecticides in furrows, spraying fungicides, rogueing, and using crop rotation and borders, were conducted more consistently in all fields; therefore, these factors were not analyzed in depth in this study.

Aphid collection. Bowl-type yellow traps (Flora; C. French Ltd.), $25 \mathrm{~cm}$ in diameter and $8 \mathrm{~cm}$ deep, were deployed in each of the study fields. The traps were filled with approximately 1 liter of a propylene glycol solution (50\% propylene glycol, $50 \%$ water, Bitrex at $12.5 \mathrm{mg} / \mathrm{liter}$, and dishwashing detergent at $0.5 \mathrm{ml} / \mathrm{liter}$ ). In all fields, at least two traps were placed five rows deep in one corner of the fields, $5 \mathrm{~m}$ apart and starting $5 \mathrm{~m}$ from the row end. The traps were installed in June near the time of plant emergence, and aphids trapped were sampled two to three times each week until mid-August. The propylene glycol solution was changed or diluted with water as necessary, depending on weather conditions. At each sampling, all trapped insects were sifted through a piece of muslin fabric before being placed in a vial (in the fabric) with $70 \%$ alcohol. The samples were kept at $4^{\circ} \mathrm{C}$ for 1 week before being inspected under a stereomicroscope for sorting and counting of the aphids. Aphid numbers are reported here as average number trapped from among all traps in each field.

PVY detection. All leaf samples collected were tested for PVY using the double-antibody sandwich ELISA using the serotype-nonspecific polyclonal antibody for PVY (PhytoDiagnostics), as described previously (15). PVY was detected (in p-nitrophenyl phosphate at $5 \mathrm{mg}$ per $10 \mathrm{ml}$ and diethanolamine at $97 \mathrm{ml} /$ liter, $\mathrm{pH}$ 9.8) and compared with positive and negative controls. Samples were considered positive when the absorbance at $405 \mathrm{~nm}$ was greater than three times the average value of the negative control as read by a Multiskan Ascent plate reader (Thermo Labsystems).

Total RNA was extracted from leaf and tuber samples ground by roller press using TRI-Reagent (Molecular Research Center, Inc.) following the manufacturer's instructions. Complementary DNA (cDNA) was synthesized as described previously by Nie and Singh (33) using the total RNA extracted. The primers, PCR conditions, and PCR product analysis were similar to those described by Nie and Singh (32). PCR was carried out with a Peltier Thermal Cycler (MJ Research) and the PCR products were imaged and analyzed (Doc-It v.2.1.0; UVP Inc.) after electrophoresis through $1.5 \%$ agarose gel in Tris-acetate-EDTA buffer (Tris base at $4.84 \mathrm{~g} / \mathrm{liter}$, glacial acetic acid at $1.142 \mathrm{ml} / \mathrm{liter}$, and $0.5 \mathrm{M}$ EDTA at $2 \mathrm{ml} / \mathrm{liter}$, $\mathrm{pH}$ 8.0). Samples were compared with negative and positive controls on each gel and were considered positive when the PVYspecific PCR product was detected.

Statistical analyses. Quantification of the relative importance of different factors, including aphid abundance, seedborne PVY, and various management practices, affecting PVY spread was assessed by logistic regression modeling. Logistic regression quantifies the relationship between one or more independent variables (or input parameters) to a dichotomous outcome variable (24). This approach is common in disease epidemiology and has been successfully applied in other potato disease pathosystems $(25,28,34,35)$. Here, the dichotomous outcome variable was PVY status of a potato plant, where $0=$ noninfected and $1=$ infected, and the input parameters used are defined in Table 2. Estimates generated by the regression analysis follow a sigmoid curve between 0 and 1 , reflecting the likelihood of a plant being infected given the state of the input parameters, which can be equivalently expressed as the population rate of PVY-infected potato plants in a field. The logistic regression estimates coefficients for each input parameter that linearly relate the value of the dependent variable to the logit (log-odds) of infection, $\log [p /(1-p)]$, where $p$ is the probability of infection. The sign and magnitude of the coefficient indicates the direction (increasing or decreasing odds of infection) and strength of its effect on the dependent variable (i.e., odds of infection). Although the regression calculations account for the dichotomous outcome of all the individual plants in the study fields, the input parameters are assessed at the field level, with each plant within

Table 2. Definitions of parameters used in the logistic regression models described in Table 4

\begin{tabular}{|c|c|}
\hline Parameter & Definition \\
\hline $\mathrm{PVY}_{\text {seed }}$ & Seedborne Potato virus $Y$ (PVY) rate (arcsin square root transformed proportion) \\
\hline Aphids $_{\text {early }}$ & Number of aphids trapped from 20 June to 3 July \\
\hline Aphids $_{\text {mid }}$ & Number of aphids trapped from 4 July to 13 July \\
\hline Aphids $_{\text {late }}$ & Number of aphids trapped from 14 July to 7 August \\
\hline $\mathrm{PVY}_{\text {seed }}-$ Aphids $_{\text {early }}$ & Interaction term linking seedborne PVY and early season aphid abundance \\
\hline $\mathrm{PVY}_{\text {July }}-$ Aphids $_{\text {mid }}$ & $\begin{array}{l}\text { Interaction term linking estimated July PVY rate in field (seedborne PVY plus new infections assessed } \\
\text { around } 20 \text { July) and midseason aphid abundance }\end{array}$ \\
\hline $\mathrm{PVY}_{\text {July }}-$ Aphids $_{\text {late }}$ & $\begin{array}{l}\text { Interaction term linking estimated July PVY rate in field (seedborne PVY plus new infections assessed } \\
\text { around } 20 \text { July) and late-season aphid abundance }\end{array}$ \\
\hline ELISA $_{\text {July }}$ & $\begin{array}{l}\text { Rate of new PVY infections determined by enzyme-linked immunosorbent assay (ELISA) leaf testing } \\
\text { around } 20 \text { July (arcsine square root transformed proportion) }\end{array}$ \\
\hline $\mathrm{Oil}_{\text {season }}$ & Number of oil sprays, whole season \\
\hline Oil $_{\text {early }}$ & Number of oil sprays prior to 20 July \\
\hline $\mathrm{Oil}_{\text {late }}$ & Number of oil sprays on or after 20 July \\
\hline $\mathrm{Oil}_{\text {rate }}$ & Rate of mineral oil application (liters/ha) \\
\hline Insecticide $_{\text {season }}$ & Number of oil sprays supplemented with insecticides, whole season \\
\hline Insecticide early & Number of oil sprays supplemented with insecticides prior to 20 July \\
\hline Insecticide $_{\text {late }}$ & Number of oil sprays supplemented with insecticides on or after 20 July \\
\hline Insecticide $_{\mathrm{CF}}$ & Number of oil sprays supplemented with insecticides of $\lambda$-cyhalothrin or flonicamid chemistries \\
\hline Insecticide $_{\text {non-CF }}$ & Number of oil sprays supplemented with insecticides of other chemistries \\
\hline Shepody & Potato cultivar planted (categorical factor) \\
\hline FL1879 & Potato cultivar planted (categorical factor) \\
\hline FL1207 & Potato cultivar planted (categorical factor) \\
\hline Goldrush & Potato cultivar planted (categorical factor) \\
\hline Innovator & Potato cultivar planted (categorical factor) \\
\hline Russet Burbank & Potato cultivar planted (categorical factor) \\
\hline CalWhite & Potato cultivar planted (categorical factor) \\
\hline Snowden & Potato cultivar planted (categorical factor) \\
\hline
\end{tabular}


that field assumed to be exposed to those parameters equivalently (e.g., local aphid abundance and number of insecticide treatments). Similarly, the results here are presented at the field level as the proportion of infected plants per field rather than the likelihood of an individual plant to be infected.

Six models with different input parameters were fit to the posttop-kill PVY infection rates. Model BEST represents the most reliable model fit to the data, including six parameters relating to virus source, vector, management efforts, and a measure of midseason PVY spread (ELISA July $_{\text {y }}$ ) as an additional parameter. A reduced model, SIMPLE, was also fit with the same parameters, except for

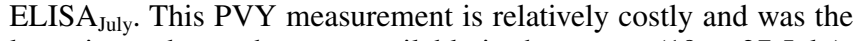
latest input data to become available in the season (19 to 27 July); therefore, it was important to determine whether a model without it could still allow adequate estimation of PVY spread up to top-kill. Four other alternative models were fit; namely, TIMING, INSTYPE, APHIDS, and CULTIVAR. In TIMING, the number of mineral oil sprays and those sprays supplemented with insecticide were divided into two parameters, each to assess the relative impact on PVY spread of sprayings before or after 20 July (oil early, $_{\text {, }}$ insecticide $_{\text {early }}$ and oil $_{\text {late }}$ insecticide late $_{\text {, }}$ respectively). In model INS-TYPE, the total number of oil sprays supplemented with insecticides were divided into two categories: those belonging to the $\lambda$-cyhalothrin or flonicamid chemistries thought to be more effective against aphids (insecticide $\mathrm{CF}_{\mathrm{F}}$ ) and other insecticides (insecticide $\left._{\text {non-CF}}\right)$. In APHIDS, several additional parameters describing aphid abundance and its interaction with PVY in the field later in the season were added to determine whether these vector-related factors are more important in early (late June), mid- (mid-July), or late season (late July to August). Finally, model CULTIVAR included parameters for the eight potato cultivars used in the study to investigate whether some cultivars are significantly more resistant to PVY spread than others.

The statistical strength of the input parameters within each model were compared using the Wald $\chi^{2}$ statistic and logistic regression coefficients to compare the effect size of the parameter. The relative performance each model as a whole was assessed primarily by comparing Akaike Information Criterion (AIC) scores. As well, the proportion of explained deviance, 1 -
$(R D / N D)$, where $R D$ and $N D$ are the residual and null deviance, respectively, and $R D$ divided by its degrees of freedom $(R D / d f)$ were calculated as indexes of how well the model explains the variance in the data set and the appropriateness of the number of included parameters, respectively. We used the likelihood ratio test as described by Hosmer and Lemeshow (24) to assess the overall significance of the models (each full model compared with an intercept-only model), for determining whether they were significantly different from one another, and for confirming the individual significance of parameters within the models. Many other input parameters were included in earlier models, such as the date of planting, timing of first and last oil and insecticide supplemented sprays relative to planting and top-kill dates, and age of the plants at top-kill, but none of these were individually significant parameters in the larger models, and they consistently reduced model performance overall.

The predictive capacity of models BEST and SIMPLE were validated using the leave-one-out cross-validation (LOOCV) technique (4) that divides the available data into a large "training set" for model construction and a smaller "prediction set" to independently test the model. Here, all the plants of one field were left out as the prediction set and the model was rebuilt with the remaining 18 fields as the training set, and this process was performed 19 times, using each field in turn as the prediction set. Thus, the PVY rate in each prediction set field was predicted by a unique model constructed with data from the training set fields, and compared with the actual PVY rates in Table 3.

All regression modeling and correlation calculations were performed with $\mathrm{R}$ version 2.7.0 (40). For all modeling input parameters and correlation calculations, ELISA ${ }_{\text {July }}, \mathrm{PVY}_{\text {seed }}$, and other measures of PVY infection rates were arcsine-square root transformed prior to analysis. These data were highly skewed proportions typically crowded near the $0 \%$ extreme, and transformation was confirmed to increase the normality of the data in all cases.

\section{Results}

Detection of PVY spread during the growing season. Initial PVY presence in the fields, assessed shortly after plant emergence in the marked plants, was detected in 9 of the 19 total fields in

Table 3. Potato virus $Y$ (PVY) spread to initially virus-free plants through the growing season (approximate weeks after planting); values are percent infection of 100 to 110 marked initially virus-free plants ${ }^{\mathrm{a}}$

\begin{tabular}{|c|c|c|c|c|c|c|c|c|}
\hline \multirow[b]{3}{*}{ Season, cultivar ${ }^{\mathbf{b}}$} & \multirow{2}{*}{\multicolumn{2}{|c|}{$\frac{\text { July (7-8 weeks) }}{\text { Leaf }}$}} & \multicolumn{4}{|c|}{ August (9-11 weeks) } & \multirow{2}{*}{\multicolumn{2}{|c|}{$\begin{array}{c}\text { Top-kill (12-15 weeks) } \\
\text { Tuber }\end{array}$}} \\
\hline & & & \multicolumn{2}{|c|}{ Leaf } & \multicolumn{2}{|c|}{ Tuber } & & \\
\hline & ELISA & RT-PCR & ELISA & RT-PCR & RT-PCR & GO-ELISA & RT-PCR & GO-ELISA \\
\hline \multicolumn{9}{|l|}{2011} \\
\hline Russet Burbank & 2.0 & 2.0 & 5.0 & 5.0 & 17.0 & 17.0 & 27.0 & 27.0 \\
\hline Innovator & 0 & 1.0 & 0 & 0 & 0 & 0 & 0 & 0 \\
\hline Goldrush 1 & 0 & 0 & 0 & 0 & 0 & 0 & 2.0 & 2.0 \\
\hline Goldrush 2 & 0 & 0 & 0 & 0 & 0 & 0 & 0 & 0 \\
\hline FL1207 & 0 & 0 & 0 & 0 & 1.0 & 1.0 & 1.0 & 1.0 \\
\hline Shepody & 1.0 & 2.0 & 3.0 & 6.0 & 10.0 & 8.0 & 11.0 & 11.0 \\
\hline Goldrush 3 & 0 & 0 & 0 & 0 & 2.0 & 2.0 & 3.0 & 3.0 \\
\hline Goldrush 4 & 0 & 0 & 0 & 0 & 0 & 0 & 2.0 & 2.0 \\
\hline CalWhite 1 & 0 & 0 & 0 & 0 & 2.0 & 2.0 & 5.0 & 5.0 \\
\hline CalWhite 2 & 1.0 & 0 & 0 & 0 & 0 & 0 & 2.0 & 2.0 \\
\hline \multicolumn{9}{|l|}{2012} \\
\hline Shepody & 0 & 0 & 3.8 & 3.8 & 4.8 & 5.8 & 7.1 & 8.0 \\
\hline Innovator 1 & 0.9 & 2.7 & 1.8 & 1.9 & 3.7 & 4.0 & 6.0 & 6.0 \\
\hline Innovator 2 & 12.4 & 14.3 & 55.8 & 69.2 & 73.1 & 72.1 & 76.2 & 76.2 \\
\hline Snowden & 2.8 & 2.8 & 2.8 & 2.8 & 2.8 & 2.8 & 1.9 & 1.9 \\
\hline Innovator 3 & 0 & 0 & 0.9 & 1.8 & 0.9 & 0.9 & 0.9 & 0.9 \\
\hline Russet Burbank 1 & 0 & 0 & 3.2 & 4.3 & 1.1 & 1.1 & 4.2 & 4.2 \\
\hline FL1879 1 & 0.9 & 0.9 & 0.9 & 3.8 & 0.9 & 3.8 & 5.7 & 5.7 \\
\hline FL1879 2 & 0 & 0.9 & 0 & 0 & 0 & 0.9 & 0.9 & 0.9 \\
\hline Russet Burbank 2 & 2.9 & 2.9 & 1.0 & 5.7 & 6.7 & 6.7 & 8.6 & 8.7 \\
\hline
\end{tabular}

${ }^{a}$ Calendar dates of planting and top-kill varied due to grower choice and weather conditions (as described in Materials and Methods); thus, dates of July and August samplings were adjusted to maintain consistent times between samplings and to sample plants at consistent maturity levels across the fields. ELISA = enzyme-linked immunosorbent assay, RT-PCR = reverse-transcription polymerase chain reaction, and GO-ELISA = grow-out ELISA.

${ }^{\mathrm{b}}$ Field season, cultivar, and field. 
2011 and 2012 (Table 1). The infections detected at this stage were considered seedborne (secondary) infections, and the highest infection rates were $5.8 \%$ in 2011 and $4.5 \%$ in 2012, consistent with seedborne PVY rates observed in previous seasons in this region (data not shown). Plants testing positive for seedborne infection were excluded from future sampling, and the remaining 100 to 110 noninfected plants were monitored for current-season (primary) PVY infection during the growing season.

Current-season spread of PVY varied considerably, from 0 to $76.2 \%$ (Table 3). Only 2 of 19 fields, both in 2011 (Innovator and Goldrush field 2), remained free of PVY spread through the entire season. It is noteworthy that no seedborne infection was detected in these two fields (Table 1, year 2011).

Most of the study fields showed detectable transmission of PVY by midseason (late July), assessed by ELISA and RT-PCR methods. PVY was detected in the selected plants in eight and nine fields with ELISA and RT-PCR, respectively, within approximately 3 weeks after initial screening (Table 3). At the time of the August sampling, approximately 3 weeks before top-kill, 14 of the 19 fields had detectable PVY in previously virus-free plants. On both the July and August sampling dates, ELISA and RT-PCR methods gave comparable results with leaf testing. The RT-PCR assessment of developing tubers taken from those same plants in August, however, detected PVY in $20 \%$ more plants overall and present in $30 \%$ more fields than was detected with ELISA. These tubers were confirmed to be PVY infected by later grow-out testing in the greenhouse (Table 3$)$. Despite the variations, a high correlation $\left(r^{2}\right.$ $=0.822$ to $0.970, n=19$ ) was found between ELISA and RT-PCR assays as well as between leaf and tuber testing. As expected, July leaf testing was relatively less correlated to the final PVY inci- dence determined after the top-kill (ELISA $r^{2}=0.687$, PCR $r^{2}=$ $0.598, n=19$ ) than was August leaf testing (ELISA $r^{2}=0.861$, PCR $\left.r^{2}=0.855, n=19\right)$. The best correlated midseason PVY test with post top-kill PVY incidence was RT-PCR testing on developing tubers in August $\left(r^{2}=0.941, n=19\right)$.

PVY-spread as a function of inoculum, vector, and management. To help explain the wide range of PVY spread observed through the season, it is useful to sort the fields according to inoculum, vector, and management factors that likely influence PVY spread. The levels of post top-kill PVY infection of previously virus-free plants in all fields were sorted into categories based on seedborne PVY status and abundance of aphids in the fields (Fig. 1). The categories were chosen based on the field showing detectable versus nondetected seedborne PVY, and having equal to or lower than (low aphid) or greater than (high aphid) the median of 45 aphids trapped per trap during the 2-week peak period of aphid abundance. Although arbitrary and not meant to substitute for the more rigorous regression analysis below, these divisions were biologically reasonable, allowed categories with nearly equal numbers of fields in each, and produced a visual impression of the interactive effects of seedborne PVY, aphids, and management on PVY spread.

Fields without detectable seedborne PVY showed far less PVY spread (mean $2.8 \%$, range 0 to $8.7 \%$ ) than fields with detected seedborne PVY (mean $15.2 \%$, range 1 to $76.2 \%$ ). High aphid fields were associated with greater overall spread, particularly in the fields with detectable seedborne PVY. Mineral oil and insecticide spraying appeared to cause substantial reduction in the spread of PVY (Fig. 1). Regardless of the category of exposure to PVY of the fields, frequent mineral oil or insecticide sprays (i.e., up to 14

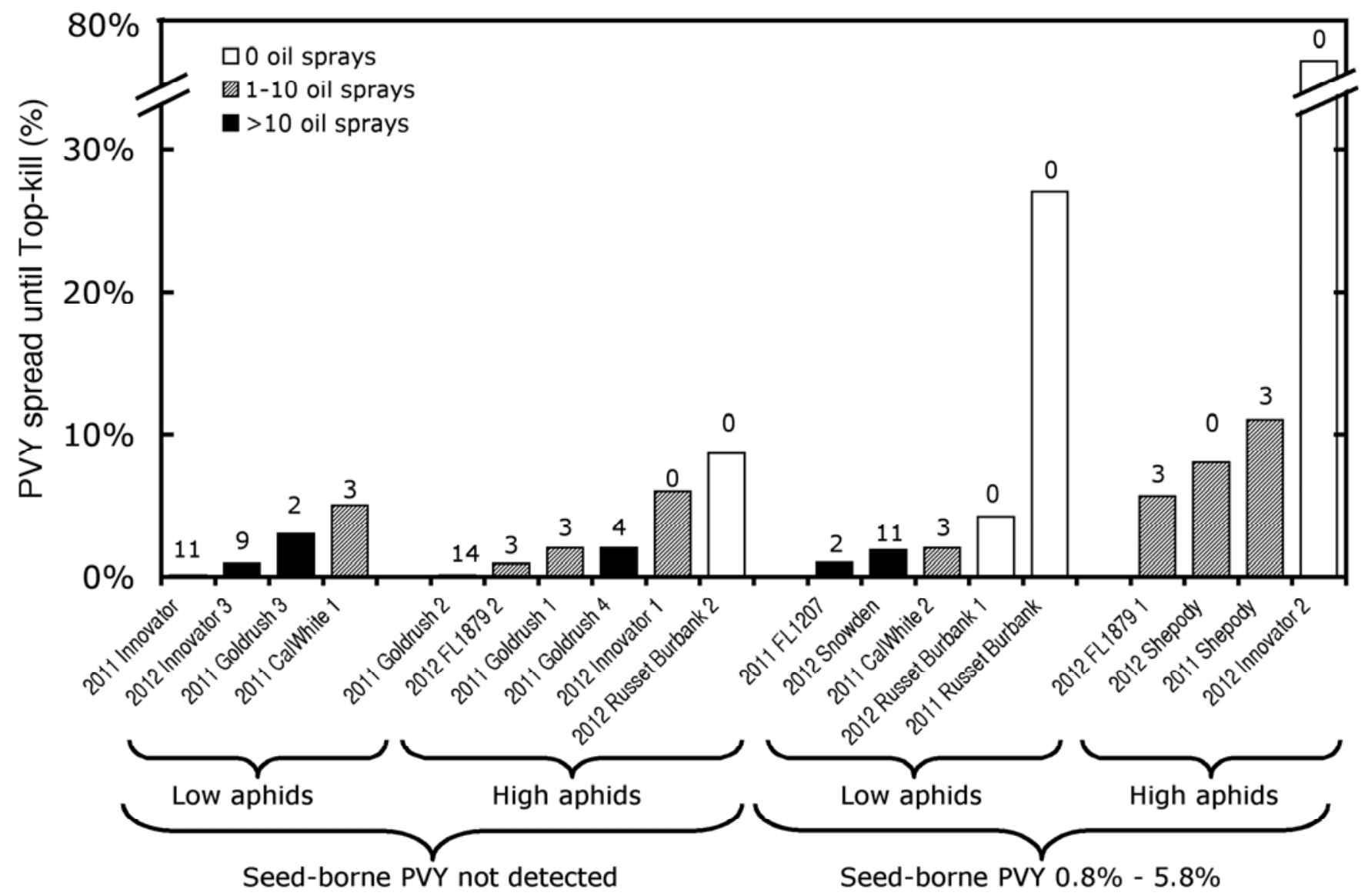

Fig. 1. Potato virus $Y(P V Y)$ spread until top-kill in initially virus-free plants selected about 5 weeks after planting as percent infection of 100 to 110 selected plants per field. Fields are sorted into four categories based on whether there was or was not detected (i.e., $>0.9 \%$ ) seedborne PVY, and whether aphid abundance was low (below median) or high (above median) during the 2-week peak period beginning 20 June each year; median aphid abundance was 45 per trap over these 2 weeks. Within each of these categories, fields are sorted by increasing infection level. Two fields with zero PVY spread, 2011 Innovator and 2011 Goldrush 2, were sprayed >10 times with mineral oil. Numbers above each bar indicate number of contact insecticides sprayed in each field throughout the season. Note the discontinuous y-axis, indicating the very high level of PVY in the 2012 Innovator 2 field. 
times each through the season) were associated with a large reduction in PVY compared with fields in the same aphid and seedborne PVY category but not sprayed at all. Often, mineral oil and insecticide sprays were used in combination although, in most fields, mineral oil was sprayed alone on many dates and, in two fields (Fig. 1, 2012 Shepody and 2012 Innovator 1), mineral oil was used alone at all sprayings. The lower rates of PVY in these fields compared with those not sprayed with mineral oil, and the statistical modeling discussed below (Tables 2 and 3), suggest that mineral oil sprays alone can reduce PVY spread. The effectiveness of insecticides alone could not be addressed in this study; however, in almost all cases, mineral oil was also sprayed with each insecticide spray; therefore, the observed effectiveness relates to the combined application of insecticides and mineral oil spraying.

Regression modeling of factors influencing PVY spread. Six logistic regression models with varying input parameters were fit to investigate the most important factors controlling PVY spread (Table 4). The model BEST most efficiently explained the variance in PVY spread because it had the lowest AIC score, indicating the most variance explained given the conservative number of PVY, aphid, and management parameters used. Alone, neither the rate of seedborne PVY ( $\left.\mathrm{PVY}_{\text {seed }}\right)$ nor the number of aphids trapped over

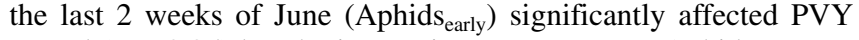
spread $(P>0.05)$ but the interaction term $\mathrm{PVY}_{\text {seed }} \times$ Aphids $_{\text {early }}$ was strongly positive, indicating the critical requirement for both virus and vector to be present in a field to cause significant PVY spread $(P=0.004)$. A midseason ELISA measurement of new PVY infections (ELISA $A_{\text {July }}$ ) was also a strongly positive factor in explaining PVY spread later in the season $(P=0.009)$. Of the management parameters, the most important were the number of mineral oil sprays through the season (oil season $_{1} P=0.05$ ) and the number of those sprays supplemented with insecticides (insecticide season,$P=$ 0.006). Both of these showed the expected negative relationship with PVY spread, with the insecticide-supplemented sprays showing a stronger and more significant effect on reducing PVY spread than the total number of oil sprays. The rate of oil application (oilrate) varied between about 1.7 and 5 liters/ha in this study but, across that range, it did not influence PVY spread significantly $(P$ $=0.125)$. Interestingly, across all explored models, oil rate $_{\text {was }}$ unexpectedly positively associated with PVY spread and, occasionally, statistically significant, and including it in the models consistently allowed better overall model fit. In all cases above where individual parameters were determined to be statistically significant or not based on the Wald $\chi^{2}$ statistic, the significance of the parameter was confirmed by a likelihood ratio test between the overall model and a separate model with the parameter of interest removed. Overall, the residual variation divided by the model $d f$ was very near unity, suggesting these seven parameters are appropriate in number and ability to explain the variance in the data set.

The model SIMPLE, including the same parameters as BEST except for ELISA $A_{\text {July }}$, retained substantial explanatory power, with most remaining parameters showing similar values as they had in BEST. SIMPLE, however, fit the data significantly more poorly than BEST $(P=0.009$ by likelihood ratio test $)$, had the highest AIC score of any model with fewer than 10 parameters, and showed relatively large overdispersion, suggesting that it is improperly parameterized. Despite the relatively poor fit of SIMPLE, it was subjected to cross-validation along with BEST to more explicitly quantify its predictive capacity, because the input parameters of SIMPLE are practically superior to any other model.

In the model TIMING, there were small differences in the coefficients of aphid, PVY, and oil $1_{\text {rate }}$ but they generally remained similar in magnitude and direction, as in BEST. After division into early and late categories, however, the oil and insecticide parameters had lower statistical support but showed clearly that the early oil sprays supplemented with insecticide (insecticide $e_{\text {early }}$ ) remained a strong and significant factor in reducing PVY spread $(P=0.022)$, whereas later insecticide-supplemented sprays (insecticide late $_{\text {la }}$ ) were not significant $(P=0.394)$. The number of oil sprays late in the season (oil late) showed a stronger and near-significant effect com- pared with the number of early sprays, suggesting that late-season oil sprays may still be effective at reducing PVY spread. In model INS-TYPE, as in TIMING, all of the non-insecticide parameters remained similar in size and direction to model BEST. The division of the insecticide season $_{\text {parameter of BEST into the reportedly more }}$ effective insecticides (insecticide ${ }_{\mathrm{CF}}$ ) and others (insecticide ${ }_{\text {non-CF}}$ ) in the INS-TYPE model showed that the $\lambda$-cyhalothrin- or flonicamid-type insecticides were more clearly associated with reduced PVY spread $(P=0.030)$ than insecticides of other types $(P=$ 0.246). Models APHIDS and CULTIVAR have substantially more parameters than BEST and whereas, overall, they explain much of the deviance in the data set, the individual parameters have generally less statistical support than the smaller models such as BEST, and the high dispersion suggests relatively poorly parameterized models. Despite this, model APHIDS weakly shows some support for the aphid abundance early in the season (late June) and the early Aphid-PVY interaction (Aphids early $_{\text {and }}$ PVY seed $\times$ Aphids $_{\text {early, }}$, respectively) as closest to statistically significant, compared with those factors later in the season (July to August). Similarly, when simply replacing the Aphids early $_{\text {and }} \mathrm{PVY}_{\text {seed }} \times$ Aphids $_{\text {early }}$ parameters of BEST with Aphids mid $_{\text {and }}$ PVY mid $\times$ Aphids $_{\text {mid }}$ or Aphids and $P V Y_{\text {late }} \times$ Aphids $_{\text {late }}$, the resulting models showed considerably higher AIC scores (mid AIC $=82.71$, late AIC $=85.62$ ), and only $\mathrm{PVY}_{\text {late }} \times$ Aphids $_{\text {late }}$ showed marginal significance $\left(\mathrm{PVY}_{\text {late }} \times\right.$ Aphids $_{\text {late }} P=0.040$ versus $P V Y_{\text {seed }} \times$ Aphids $_{\text {early }} P=0.004$ ) (models not shown). The final alternative model, CULTIVAR, included parameters for the eight different potato cultivars planted during the study, each of which were planted in one to four fields. None of the individual cultivars showed any significant effect on PVY spread, nor was there any indication that cultivars with more replication (e.g., Goldrush; four fields, $P=0.598$ ) were any closer to significantly related to PVY spread than cultivars with less replication (Snowden; one field, $P=0.481$ ). Although all of these four alternative models had higher AIC scores than BEST, none of them showed a significantly poorer overall fit to the data, as confirmed by likelihood ratio test at $\alpha=0.05$.

In BEST, model output correlated closely with actual PVY spread (Table 5), with the average error between model output and actual PVY spread in the 19 fields only being $1.12 \%$. This model was validated by removing each field in turn and building the model using the remaining 18 fields (19-fold LOOCV). The model showed considerable robustness, because the correlation between predicted PVY spread in fields independent of the model fitting and the actual PVY spread in those fields remained high $\left(r^{2}=\right.$ 0.857 ), with an average error of $4.5 \%$. The model SIMPLE also initially showed close correlation between model output and actual PVY spread, with an average error of $1.62 \%$. However, when subjected to LOOCV, the predictive capacity of SIMPLE dropped considerably, with the correlation between model predictions and actual PVY spread dropping to $r^{2}=0.177$ and an average error of $7.2 \%$.

\section{Discussion}

The results of this study show that virus and vector abundance can generate a great potential for substantial PVY spread during the season, whereas crop management practices, specifically insecticide and mineral oil spraying, can greatly reduce PVY spread. In the regression model BEST, and generally with the other models as well, the statistically strongest individual biotic factor associated with PVY spread was the interaction term PVY seed $\times$ Aphids $_{\text {early }}$, integrating the two essential components of PVY transmissionvirus source and vector-into an index that can be thought of as "inoculum pressure." The statistically strongest management factor explaining PVY spread across all models was the number of mineral oil sprays supplemented with insecticide.

The statistical models developed in this study could largely explain the ultimate spread of PVY through the growing season. The final selected model, BEST, had a strong explanatory power but also has potential as a predictive model that could be used to advise growers on the PVY status of their crop. Modeling approaches 
Table 4. Multiple logistical regression models for explaining post top-kill Potato virus $Y$ (PVY) infection of initially virus-free plants ${ }^{\mathrm{a}}$

\begin{tabular}{|c|c|c|c|c|c|c|c|}
\hline \multirow[b]{2}{*}{ Model, parameter ${ }^{b}$} & \multicolumn{4}{|c|}{ Maximum likelihood estimates } & \multicolumn{3}{|c|}{ Model performance } \\
\hline & $\mathbf{R C}$ & SE & Wald $\chi^{2}$ & $P$ value ${ }^{c}$ & AIC & ED & Dispersion \\
\hline \multicolumn{8}{|l|}{ BEST } \\
\hline Intercept & -2.738 & 0.396 & -6.919 & $4.55 \times 10^{-12 *}$ & 81.88 & 0.974 & 1.014 \\
\hline $\mathrm{PVY}_{\text {seed }}$ & 2.655 & 1.736 & 1.530 & 0.126 & & & \\
\hline Aphids $_{\text {early }}$ & -0.188 & 0.189 & -0.993 & 0.321 & & & \\
\hline PVY $_{\text {seed }} \times$ Aphids $_{\text {early }}$ & 0.032 & 0.011 & 2.867 & $0.004 *$ & & & \\
\hline ELISA $_{\text {July }}$ & 5.726 & 2.181 & 2.626 & $0.009 *$ & & & \\
\hline Oil $_{\text {season }}$ & -0.144 & 0.074 & -1.960 & $0.050 *$ & & & \\
\hline Insecticide $_{\text {season }}$ & -0.177 & 0.064 & -2.759 & $0.006^{*}$ & & & \\
\hline Oil $_{\text {rate }}$ & 0.246 & 0.161 & 1.532 & 0.125 & & & \\
\hline \multicolumn{8}{|l|}{ SIMPLE } \\
\hline Intercept & -2.560 & 0.363 & -7.062 & $1.64 \times 10^{-12 *}$ & 86.65 & 0.958 & 1.494 \\
\hline $\mathrm{PVY}_{\text {seed }}$ & 4.385 & 1.644 & 2.667 & $0.008 *$ & & & \\
\hline Aphids $_{\text {early }}$ & 0.052 & 0.169 & 0.308 & 0.758 & & & \\
\hline PVY $_{\text {seed }} \times$ Aphids $_{\text {early }}$ & 0.047 & 0.009 & 5.080 & $3.78 \times 10^{-7 *}$ & & & \\
\hline Oil $_{\text {season }}$ & -0.167 & 0.074 & -2.257 & $0.024 *$ & & & \\
\hline Insecticide $_{\text {season }}$ & -0.128 & 0.063 & -2.028 & $0.043 *$ & & & \\
\hline Oil $_{\text {rate }}$ & 0.190 & 0.166 & 1.140 & 0.254 & & & \\
\hline \multicolumn{8}{|l|}{ TIMING } \\
\hline Intercept & -2.882 & 0.409 & -7.050 & $1.79 \times 10^{-12 *}$ & 83.72 & 0.979 & 0.999 \\
\hline $\mathrm{PVY}_{\text {seed }}$ & 3.989 & 1.943 & 2.053 & $0.040 *$ & & & \\
\hline Aphids $_{\text {early }}$ & -0.082 & 0.203 & -0.405 & 0.686 & & & \\
\hline PVY $_{\text {seed }} \times$ Aphids $_{\text {early }}$ & 0.032 & 0.011 & 2.791 & $0.005 *$ & & & \\
\hline ELISA $_{\text {July }}$ & 4.661 & 2.368 & 1.968 & $0.049 *$ & & & \\
\hline Oil $_{\text {early }}$ & 0.218 & 0.278 & 0.785 & 0.432 & & & \\
\hline Oillate $_{\text {la }}$ & -0.469 & 0.301 & -1.561 & 0.119 & & & \\
\hline Insecticide $_{\text {early }}$ & -0.283 & 0.124 & -2.292 & $0.022 *$ & & & \\
\hline Insecticide $_{\text {late }}$ & -0.094 & 0.110 & -0.852 & 0.394 & & & \\
\hline Oil $_{\text {rate }}$ & 0.393 & 0.221 & 1.774 & 0.076 & & & \\
\hline \multicolumn{8}{|l|}{ INS-TYPE } \\
\hline Intercept & -2.814 & 0.427 & -6.584 & $4.57 \times 10^{-11 *}$ & 83.59 & 0.975 & 1.087 \\
\hline $\mathrm{PVY}_{\text {seed }}$ & 3.126 & 1.964 & 1.592 & 0.111 & & & \\
\hline Aphids $_{\text {early }}$ & -0.166 & 0.194 & -0.853 & 0.393 & & & \\
\hline PVY $_{\text {seed }} \times$ Aphids $_{\text {early }}$ & 0.031 & 0.011 & 2.687 & $0.007 *$ & & & \\
\hline ELISA July $_{\text {Jul }}$ & 5.689 & 2.175 & 2.616 & $0.009 *$ & & & \\
\hline Oil $_{\text {season }}$ & -0.128 & 0.079 & -1.615 & 0.106 & & & \\
\hline Insecticide $_{\mathrm{CF}}$ & -0.219 & 0.101 & -2.166 & $0.030 *$ & & & \\
\hline Insecticide $_{\text {non-CF }}$ & -0.127 & 0.109 & -1.159 & 0.246 & & & \\
\hline Oil $_{\text {rate }}$ & 0.207 & 0.166 & 1.346 & 0.178 & & & \\
\hline \multicolumn{8}{|l|}{ APHIDS } \\
\hline Intercept & -2.737 & 0.726 & -3.770 & $1.63 \times 10^{-4 *}$ & 89.30 & 0.975 & 1.510 \\
\hline $\mathrm{PVY}_{\text {seed }}$ & -0.703 & 5.526 & -0.127 & 0.899 & & & \\
\hline Aphids $_{\text {early }}$ & -0.398 & 0.338 & -1.178 & 0.239 & & & \\
\hline Aphids $_{\text {mid }}$ & 0.791 & 1.853 & 0.427 & 0.669 & & & \\
\hline Aphids $_{\text {late }}$ & -0.096 & 0.939 & -0.103 & 0.918 & & & \\
\hline PVY $_{\text {seed }} \times$ Aphids $_{\text {early }}$ & 0.071 & 0.091 & 0.789 & 0.430 & & & \\
\hline $\mathrm{PVY}_{\text {July }} \times$ Aphids $_{\text {mid }}$ & -0.111 & 0.195 & -0.571 & 0.568 & & & \\
\hline $\mathrm{PVY}_{\text {July }} \times$ Aphids $_{\text {late }}$ & 0.076 & 0.152 & 0.499 & 0.618 & & & \\
\hline ELISA $_{\text {July }}$ & 6.643 & 9.142 & 0.727 & 0.467 & & & \\
\hline Oil $_{\text {season }}$ & -0.135 & 0.081 & -1.670 & 0.095 & & & \\
\hline Insecticide $_{\text {season }}$ & -0.167 & 0.084 & -1.986 & $0.047 *$ & & & \\
\hline Oil $_{\text {rate }}$ & 0.187 & 0.242 & 0.774 & 0.439 & & & \\
\hline \multicolumn{8}{|l|}{ CULTIVAR } \\
\hline Intercept & -2.365 & 0.933 & -2.534 & $0.011 *$ & 93.52 & 0.980 & 2.199 \\
\hline $\mathrm{PVY}_{\text {seed }}$ & -1.463 & 9.893 & -0.148 & 0.883 & & & \\
\hline Aphids $_{\text {early }}$ & -0.528 & 0.857 & -0.616 & 0.538 & & & \\
\hline PVY $_{\text {seed }} \times$ Aphids $_{\text {early }}$ & 0.068 & 0.039 & 1.743 & 0.081 & & & \\
\hline ELISA July $_{\text {Jul }}$ & 10.387 & 9.637 & 1.078 & 0.281 & & & \\
\hline Oil $_{\text {season }}$ & -0.413 & 0.346 & -1.195 & 0.232 & & & \\
\hline Insecticide $_{\text {season }}$ & -0.141 & 0.114 & -1.238 & 0.216 & & & \\
\hline Oil $_{\text {rate }}$ & 1.110 & 0.952 & 1.165 & 0.244 & & & \\
\hline FL1879 & -0.221 & 0.668 & -0.331 & 0.741 & & & \\
\hline FL1207 & 2.179 & 2.456 & 0.887 & 0.375 & & & \\
\hline Goldrush & -0.457 & 0.867 & -0.527 & 0.598 & & & \\
\hline Innovator & -2.285 & 1.859 & -1.229 & 0.219 & & & \\
\hline Russet Burbank & -0.084 & 1.527 & -0.055 & 0.956 & & & \\
\hline CalWhite & -1.270 & 2.547 & -0.499 & 0.618 & & & \\
\hline Snowden & -1.226 & 1.741 & -0.704 & 0.481 & & & \\
\hline
\end{tabular}

${ }^{a} \mathrm{RC}=$ regression coefficient, $\mathrm{SE}=$ standard error, $\mathrm{AIC}=$ Akaike Information Criterion, and ED = explained deviance.

${ }^{\mathrm{b}}$ Enzyme-linked immunosorbent assay $\left(\right.$ ELISA $\left._{\text {July }}\right)$ and $\mathrm{PVY}_{\text {seed }}$ data were arcsine-square root transformed prior to model fitting.

c An asterisk (*) indicates parameter significant at $P=0.05$. 
have been attempted in the past to explain aphid-vectored potyvirus spread in crops, including the PVY-potato pathosystem $(14,41)$. Using similar regression approaches to this study, Sigvald (42) and Kirchner et al. (26) showed that seedborne PVY and aphid flights, particularly early in the season, strongly explained ultimate PVY incidence in multiseason studies conducted in Sweden and Finland potato fields, respectively. These correlations were strong despite in one case (42) using regional-not fieldspecific-aphid abundance and not accounting for differences in field management.

This study has also shown that midseason PVY testing is indicative of ultimate spread of PVY at season end, and that it is possible to accurately forecast PVY spread with midseason testing and knowledge of virus, vector, and management practices. The objectives of the midseason sampling were to assess how well early PVY testing-at different times and on different tissues-correlates with final PVY after top-kill. ELISA and RT-PCR detection on the same plants were all highly correlated but RT-PCR typically showed higher rates of PVY detection than ELISA. Furthermore, RT-PCR identified more widespread PVY infection directly in developing and dormant tubers that cannot be reliably tested using ELISA, confirming the greater flexibility and sensitivity of this technique for midseason PVY testing $(15,44)$. Although RT-PCR assays of developing tubers yielded the most detections, this assay was also the most costly of the midseason tests and occurred so late in the season that its practical value is limited. It is clear in Table 3 that the most rapid rate of new PVY detections occurred several weeks after the late-June to early-July peak aphid abundance but infection may occur substantially earlier than detection of PVY. Both through the model APHIDS and more simply by replacing the early aphid abundance with aphid abundances assessed later in the season, it is clear that the most relevant aphids for predicting PVY spread are those captured early in the season. Furthermore, the model TIMING suggested that applications of insecticides earlier in the season, presumably interfering with PVY transmission then, better explained reductions in the later spread of PVY than did late applications of insecticides. In a study in 2010 in the same potato-growing areas of New Brunswick and 2011 in the same fields as this study, Pelletier et al. (36) showed that numbers of aphids with detectable PVY in their stylets peaked in late June. Indeed, out of all aphids found to be carrying PVY during the 10 -week sampling seasons, $69 \%$ of them were found in only the 2 weeks between 18 June and 2 July 2010 and $59 \%$ in the 2 weeks between 20 June and 3 July 2011. Because PVY does not persist in the stylet of aphids, presumably substantial PVY spread may take place during this early period, despite the relatively low level of detections during sampling 3 weeks later. Slow viral replication and transduction through the plant tissues may make detection of PVY less likely until later in the season and more likely in the tubers than leaves that were not the site of infection $(15,43)$.

Midseason testing alone is not adequate to forecast PVY infection at the end of the season but it seems to be a required element along with other factors to make a reliably predictive model in BEST. Furthermore, of the range of dates and techniques used during midseason testing, the relatively rapid, inexpensive, and early-season July ELISA leaf testing was adequate for use in the modeling. The model SIMPLE was produced to explore whether all the other model factors, available several weeks earlier and without the time and expense of midseason testing of the crop, could still adequately predict PVY spread by the end of the season. However, as the model validation showed (Table 5), without this critical indicator of PVY taken midseason, the reliability of prediction dropped considerably, leading to a level of uncertainty in many of the study fields that would make the prediction not practically useful.

This study followed the typical management practices of a variety of commercial producers, and shows that the crop spraying practices of some of those growers can effectively reduce PVY spread. Many studies have demonstrated the efficacy of mineral oil for reducing spread of PVY between potato plants, whereas insecticides have shown more mixed results (1). Here, we have documented reductions in PVY transmission in commercial fields sprayed with mineral oil similar to observations in controlled field trials (7) and laboratory experiments (8). In our study, mineral oil sprays ranged from about 1.7 to 5 liters/ha, below the manufacturer's recommended rate. Interestingly, the range of rates of oil applied to the field did not have a clear effect on PVY spread, generally being in the opposite direction to expectations and of low statistical significance. It may be that oil $1_{\text {rate }}$ is not a variable truly independent of PVY spread. The growers managing the four fields sprayed with the highest oil $1_{\text {rate }}$ in this study have, in previous years, experienced unusually high rates of PVY (to nearly 40\%) which may have influenced their choice of oil $l_{\text {rate }}$ in later seasons; this could cause a spurious relationship between oil ${ }_{\text {rate }}$ and PVY that was, in fact, due to some other factor in those fields. Further complicating the interpretation of oil application rates, the data here

Table 5. Explanatory and predictive performance of regression models BEST and SIMPLE

\begin{tabular}{|c|c|c|c|c|c|}
\hline \multirow[b]{2}{*}{ Season, cultivar, field } & \multirow[b]{2}{*}{ PVY spread ${ }^{\mathrm{a}}$} & \multicolumn{2}{|c|}{ Model BEST } & \multicolumn{2}{|c|}{ Model SIMPLE } \\
\hline & & Model estimate & Validated prediction & Model estimate & Validated prediction \\
\hline \multicolumn{6}{|l|}{2011} \\
\hline Russet Burbank & 27.0 & 23.5 & 12.4 & 21.5 & 9.8 \\
\hline Innovator & 0.0 & 0.6 & 0.6 & 0.7 & 0.7 \\
\hline Goldrush 1 & 2.0 & 2.3 & 2.3 & 2.6 & 2.7 \\
\hline Goldrush 2 & 0.0 & 0.2 & 0.3 & 0.3 & 0.4 \\
\hline FL1207 & 1.0 & 0.9 & 0.8 & 1.0 & 0.9 \\
\hline Shepody & 11.0 & 12.2 & 14.6 & 13.4 & 18.0 \\
\hline Goldrush 3 & 3.0 & 1.9 & 1.8 & 1.5 & 1.3 \\
\hline Goldrush 4 & 2.0 & 1.2 & 1.2 & 1.3 & 1.2 \\
\hline CalWhite 1 & 5.0 & 2.3 & 1.8 & 2.6 & 2.1 \\
\hline CalWhite 2 & 2.0 & 4.6 & 6.0 & 3.8 & 4.4 \\
\hline \multicolumn{6}{|l|}{2012} \\
\hline Shepody & 8.0 & 6.5 & 4.1 & 9.9 & 12.6 \\
\hline Innovator 1 & 6.0 & 7.3 & 22.8 & 3.7 & 2.5 \\
\hline Innovator 2 & 76.2 & 76.3 & 97.4 & 75.3 & 5.6 \\
\hline Snowden & 1.9 & 1.6 & 1.3 & 1.0 & 0.7 \\
\hline Innovator 3 & 0.9 & 0.5 & 0.4 & 0.6 & 0.5 \\
\hline Russet Burbank 1 & 4.2 & 7.8 & 15.4 & 11.2 & 19.9 \\
\hline FL1 & 5.7 & 5.4 & 5.3 & 5.4 & 5.3 \\
\hline FL2 & 0.9 & 1.7 & 1.7 & 1.9 & 2.0 \\
\hline Russet Burbank 2 & 8.7 & 8.7 & 10.5 & 8.3 & 2.5 \\
\hline$r^{2}$ & $\ldots$ & 0.969 & 0.857 & 0.949 & 0.177 \\
\hline
\end{tabular}

a Actual Potato virus Y (PVY) spread. 
only describe rate per field area, not taking into account leaf canopy coverage and actual deposition rates on the plants. Thus, the simple number of sprays through the season was found to be related to PVY spread most consistently through the analyses.

Sprayed insecticides generally have a poor record in controlling PVY spread (22) but, through all the models produced here, the number of insecticide-supplemented sprays was consistently important for explaining the reductions in PVY spread observed in the field. The data presented here do not support the hypothesis that insecticides are reducing PVY spread via changing aphid abundance. Abundance during the important early-season aphid peak was not significantly lower in insecticide-sprayed fields, and the greater differences seen in their abundance was at larger regional and annual scales. It seems unlikely that insecticides applied to any one field would have a substantial effect on the wider regional population. Furthermore, if insecticides were reducing PVY spread indirectly via lowered aphid abundance, then it would be expected that the indirect insecticide spraying factor would be less statistically relevant to PVY spread than the more direct aphid abundance factor-but the opposite was true in the models produced in this study. Thus, it seems that the strong effects of insecticide sprays observed here are more likely due to interference with transmission of PVY between plants. Regardless of the mechanism involved, the mineral oil and insecticide spraying regimes used in many of the fields in this study appeared effective for reducing PVY transmission in the field. Importantly, the early-season insecticide-supplemented oil sprays were more significant in reducing PVY spread than later sprays according to model TIMING, while the late-season mineral oil sprays were statistically stronger than late-season insecticides. Taken together, this could indicate that combined oil and insecticide sprays are important early in the season, whereas continuing oil spraying late in the season with or without insecticide may also be important in reducing PVY spread.

Specific types of insecticides have shown some success in reducing PVY spread, such as the $\lambda$-cyhalothrin form of synthetic pyrethroids (1). Although they may not act quickly enough to prevent aphids from acquiring PVY from an infected plant, their relatively rapid incapacitation effect may reduce the ability of aphids to travel to and infect other plants $(10,21)$. Flonicamid, a novel insecticide outside the pyrethroid family, has also shown rapid antifeedant effects but little research exists to quantify its effect on PVY spread (31). Both these types of insecticides and a variety of others were widely used in combination with mineral oil by growers in this study, and the model INS-TYPE gives some evidence that the $\lambda$-cyhalothrin and flonicamid insecticides may be more effective than other insecticide types at reducing PVY spread. This evidence should be taken cautiously, however, because growers using these novel and typically more expensive insecticides may also have employed other innovative and effective practices not accounted for in this study. Similar to the unexpected results with oil rate $_{\text {, the }}$ insecticide $_{\mathrm{CF}}$ parameter may be more of an indicator, co-linear with generally more effective approaches by a grower to managing PVY spread, and not purely an effect of the insecticide chemistry per se. This study suggests that combined mineral oil and insecticide strongly reduces PVY spread and more so than mineral oil alone. Elsewhere, combined use of mineral oil and insecticides has been reported to reduce PVY spread (37). Mixtures of the pyrethroid WL85871 (a form of cypermethrin) and mineral oil gave better control of PVY spread by Myzus persicae than either component alone (20). Martín-López et al. (28) reported that the combination of the in-furrow insecticide imidacloprid with mineral and soya oils resulted in higher aphid mortality and reduced PVY spread compared with plots only treated with imidacloprid before planting.

There are several management practices other than insecticide and mineral oil spraying which could be important for PVY management but were not found to be significant or could not be analyzed in this study. Eight different cultivars, generally considered susceptible to PVY, were planted in the study fields, as chosen by the participating growers. The model CULTIVAR showed no evi- dence that cultivar-differences were significant in PVY spread, though the replication of the cultivars was uneven and low, and this study was not as ideal for addressing this question as a controlled and replicated laboratory or field test planting. Other factors such as in-furrow insecticide application, crop border treatments, crop rotation, and rogueing were employed widely by the growers, and the complete invariability of some practices (such as all growers using in-furrow insecticide) made it impossible to assess their effects on PVY spread. Some practices were also difficult to accurately quantify and, thus, statistically analyze, such as the different crops or schedules of rotation or the varying efficiency of rouging by different growers with different cultivars. The timing of first and last mineral oil sprays is likely important in PVY spread but, among the study fields, variability in those dates were low and, thus, the data did not show a strong statistical trend over their narrow ranges.

We are confident in the potential of the regression model BEST produced in this study, because it uses relatively few factors and assumptions of mechanistic links between them, all the factors are local to the specific field, and they include a midseason measure of PVY spread strongly indicative of future spread in the field. This regression approach is also practical; data for the few factors used in the model are easy to obtain and available by mid- to late July, 5 to 7 weeks before typical top-kill dates. In practice, results of a model such as this could inform the grower of the likelihood of the crop exceeding a certain threshold PVY level at harvest, and influence future management decisions such as the date of top-killing.

Perhaps the most obvious factor in PVY spread in this study was the planting of PVY-infected seed. The initial PVY testing to quantify seedborne PVY revealed that only 10 of the 19 study fields were planted with undetectable levels of virus in the seed, and the others carried up to $5.8 \%$ PVY-infected seed at planting. This serves as the source PVY inoculum not only in the planted fields but also for surrounding fields; taking steps to reduce the likelihood of planting PVY-infected seed would greatly reduce the potential for PVY spread and the costs associated with combating it and absorbing yield losses. It is clear from our data that fields planted with PVY-infected seed had a great potential for PVY spread to healthy plants during the season that could only partly be mitigated by the considerable effort and expense of insecticide and mineral oil application through the growing season.

\section{Acknowledgments}

We thank Canada/New Brunswick Embracing Innovation in Agriculture and Agri-Food Program for funding; participating growers for providing field facilities and relevant information; A. Gallagher, M. Hampsey, and M. Pelletier for their technical help; and Y. Pelletier, F. Baerlocher, and L. Jesson for helpful reviews of the manuscript.

\section{Literature Cited}

1. Al-Mrabeh, A., Anderson E., Torrance, L., Evans, A., and Fenton B. 2010. A Literature Review of Insecticide and Mineral Oil Use in Preventing the Spread of Non-persistent Viruses in Potato Crops. Agriculture and Horticulture Development Board, Warwickshire, UK.

2. Ameline, A., Couty, A., Martoub, M., and Giordanengo, P. 2009. Effects of mineral oil application on the orientation and feeding behaviour of Macrosiphum euphorbiae (Homoptera: Aphidae). Acta Entomol. Sin. 52:617-623.

3. Ameline, A., Couty, A., Martoub, M., Sourice, S., and Giordanengo, P. 2010. Modification of Macrosiphum euphorbiae colonisation behaviour and reproduction on potato plants treated by mineral oil. Entomol. Exp. Appl. 135:77-84.

4. Arlot, S., and Celisse, A. 2010. A survey of cross-validation procedures for model selection. Stat. Surv. 4:40-79.

5. Basky, Z. 2002. The relationship between aphid dynamics and two prominent potato viruses (PVY and PLRV) in seed potatoes in Hungary. Crop Prot. 21:823-827.

6. Basky, Z., and Almasi, A. 2005. Differences in aphid transmissibility and translocation between PVYN and PVYO isolates. J. Pestic. Sci. 78:67-75.

7. Boiteau, G., Singh, M., and Lavoie, J. 2009. Crop border and mineral oil sprays used in combination as physical control methods of the aphid-transmitted Potato virus $Y$ in potato. Pest Manage. Sci. 65:255-259.

8. Bradley, R. H. E., Moore, C. A., and Pond, D. D. 1966. Spread of potato virus Y curtailed by oil. Nature 209:1370-1371.

9. Cervantes, F. A., and Alvarez, J. M. 2008. Role of hairy nightshade Sola- 
num sarrachoides (Sendtner) in the transmission of Potato virus $Y$ (PVY) strains by aphids and study of different PVY strains reaction on Solanum tuberosum (Linnaeus). (Abstr.) Phytopathology 98:S190.

10. Collar, J. L., Avilla, C., Duque, M., and Fereres, A. 1997. Behavioral response and virus vector ability of Myzus persicae (Homoptera: Aphididae) probing on pepper plants treated with aphicides. J. Econ. Entomol. 90:16281634.

11. Crosslin, J. M. 2013. PVY: an old enemy and a continuing challenge. Am. J. Potato Res. 90 1:2-6.

12. Dessureault, M., Prasad, R., Meberg, H., and Teasdale, C. 2011. Controlling aphid-vectored viruses for organic seed potato production: literature and knowledge review. http://www.certifiedorganic.bc.ca/programs/osdp/I122_FINAL\%20Report.pdf

13. Difonzo, C. D., Ragsdale, D. W., Radcliffe, E. B., Gudmestad, N. C., and Secor, G. A. 1996. Crop borders reduce potato virus Y incidence in seed potato. Ann. Appl. Biol. 129:289-302.

14. Doering, T. F. 2011. Potential and limitations of plant virus epidemiology: lessons from the Potato virus $Y$ pathosystem. Potato Res. 54:341-354.

15. Fageria, M. S., Singh, M., Nanayakkara, U., Pelletier, Y., Nie, X., and Wattie, D. 2013. Monitoring current season spread of Potato Virus $Y$ in potato fields using ELISA and real-time RT-PCR. Plant Dis. 97:641-644.

16. Fageria, M. S., Singh, M., Nanayakkara, U., Wattie, D., Pelletier, Y., and. Nie, X. 2011. Monitoring current season spread of Potato virus $Y$ in seed potato fields. (Abstr.) Am. J. Potato Res. Online publication. doi:10.1007/s12230-011-9230-3

17. Fereres, A. 2000. Barrier crops as a cultural control measure of non-persistently transmitted aphid-borne viruses. Virus Res. 71:221-231.

18. Fereres, A., and Moreno, A. 2009. Behavioural aspects influencing plant virus transmission by homopteran insects. Virus Res. 141:158-168.

19. Fereres, A., Perez, P., Gemeno, C., and Ponz, F. 1993. Transmission of Spanish pepper-PVY and potato-PVY isolates by aphid (Homoptera, Aphididae) vectors-epidemiologic implications. Environ. Entomol. 22:1260-1265.

20. Gibson, R. W., and Rice, A. D. 1986. The combined use of mineral-oils and pyrethroids to control plant-viruses transmitted nonpersistently and semipersistently by Myzus persicae. Ann. Appl. Biol. 109:465-472.

21. Gibson, R. W., Rice, A. D., and Sawicki, R. M. 1982. Effects of the pyrethroid deltamethrin on the acquisition and inoculation of viruses by Myzus persicae. Ann. Appl. Biol. 100:49-54.

22. Gray, S., De Boer, S., Lorenzen, J., Karasev, A., Whitworth, J., Nolte, P., Singh, R., Boucher, A., and Xu, H. 2010. Potato virus $Y$ : an evolving concern for potato crops in the United States and Canada. Plant Dis. 94:13841397.

23. Hooks, C. R. R., and Fereres, A. 2006. Protecting crops from non-persistently aphid-transmitted viruses: a review on the use of barrier plants as a management tool. Virus Res. 120:1-16.

24. Hosmer, D. W., and Lemeshow, S. 2000. Applied Logisitc Regression, 2nd ed. John Wiley \& Sons, New York.

25. Johnson, D. A., Alldredge, J. R., and Hamm, P. B. 1998. Expansion of potato late blight forecasting models for the Columbia Basin of Washington and Oregon. Plant Dis 82:642-645.

26. Kirchner, S. M., Doering, T. F., Hiltunen, L. H., Virtanen, E., and Valkonen, J. P. T. 2011. Information-theory-based model selection for determining the main vector and period of transmission of Potato virus Y. Ann. Appl. Biol. 159:414-427

27. Loebenstein, G., and Raccah, B. 1980. Control of non-persistently transmitted aphid-borne viruses. Phytoparasitica 8:221-235.
28. Martín-López, B., Varela I., Marnotes, S., and Cabaleiro, C. 2006. Use of oils combined with low doses of insecticide for the control of Myzus persicae and PVY epidemics. Pest Manage. Sci. 62:372-378.

29. Martoub, M., Couty, A., Giordanengo, P., and Ameline, A. 2011. Opposite effects of different mineral oil treatments on Macrosiphum euphorbiae survival and fecundity. J. Pestic. Sci. 84:229-233

30. McDonald, J. G., and Coleman, W. K. 1984. Detection of potato virus-Y and virus-S in tubers by ELISA after breaking of dormancy with bromoethane or rindite. Am Potato J. 61:619-622.

31. Morita, M., Ueda, T., Yoneda, T., Koyanagi, T., and Haga, T. 2007. Flonicamid, a novel insecticide with a rapid inhibitory effect on aphid feeding. Pest Manage. Sci. 63:969-973.

32. Nie, X., and Singh, R. P. 2001. A novel usage of random primers for multiplex RT-PCR detection of virus and viroid in aphids, leaves, and tubers. J. Virol. Methods 91:37-49.

33. Nie, X. Z., and Singh, R. P. 2002. A new approach for the simultaneous differentiation of biological and geographical strains of Potato virus $Y$ by uniplex and multiplex RT-PCR. J. Virol. Methods 104:41-54.

34. Nitzan, N., Evans, M., and Johnson, D. A. 2006. Colonization of potato plants after aerial infection by Colletotrichum coccodes, causal agent of potato black dot. Plant Dis. 90:999-1003.

35. Olanya, O. M., Honeycutt, C. W., Larkin, R. P., Griffin, T. S., He, Z., and Halloran, J. M. 2009. The effect of cropping systems and irrigation management on development of potato early blight. J. Gen. Plant Pathol. 75 4:267 275.

36. Pelletier, Y., Nie, X., Giguere, M., Nanayakkara, U., Maw, E., and Foottit, R. 2012. A new approach for the identification of aphid vectors (Hemiptera: Aphididae) of Potato virus Y. J. Econ. Entomol. 105:1909-1914.

37. Perring, T. M., Gruenhagen, N. M., and Farrar, C. A. 1999. Management of plant viral diseases through chemical control of insect vectors. Annu. Rev. Entomol. 44:457-481.

38. Powell, G. 1992. The effect of mineral-oil on stylet activities and potato virus-Y transmission by aphids. Entomol. Exp. Appl. 63:237-242.

39. Ragsdale, D. W., Radcliffe, E. B., and Di Fonzo, C. D. 2001. Epidemiology and field control of PVY and PLRV. Pages 237-270 in: Virus and Virus-like Diseases of Potatoes and Production of Seed-Potatoes. G. Loebenstein, P. Berger, A. A. Brunt, and R. Lawson, eds. Kluwer Academic Publishers, Dordrecht, The Netherlands.

40. R Development Core Team. 2008. R: A Language and Environment for Statistical Computing. R Foundation for Statistical Computing, Vienna. http://www.R-project.org

41. Robert, Y., Woodford, J. A. T., and Ducray-Bourdin, D. G. 2000. Some epidemiological approaches to the control of aphid-borne virus diseases in seed potato crops in northern Europe. Virus Res. 71:33-47.

42. Sigvald, R. 1987. Aphid migration and the importance of some aphid species as vectors of potato-virus $\mathrm{Y}^{\mathrm{O}}\left(\mathrm{PVY}^{\mathrm{O}}\right)$ in Sweden. Potato Res. 30:267 283.

43. Silva, M. S., Wellink, J., Goldbach, R. W., and van Lent, J. W. M. 2002. Phloem loading and unloading of Cowpea mosaic virus in Vigna unguiculata. J. Gen. Virol. 83:1493-1504.

44. Singh, M., Singh, R. P., Fageria, M. S., Nie, X., Coffin, R., and Hawkins, G. 2013. Optimization of a real-time RT-PCR assay and its comparison with ELISA, conventional RT-PCR and the grow-out test for large scale diagnosis of Potato virus $Y$ in dormant potato tubers. Am. J. Potato Res. 90:43-50.

45. Wrobel, S. 2009. The retention of PVY in the stylet of Myzus persicae Sulz. after the application of mineral oil on potato plants. Plant Breed. Seed Sci. $60: 3-12$. 